\title{
Deep Brain Stimulation of the Nucleus Accumbens Shell Attenuates Cocaine Priming-Induced Reinstatement of Drug Seeking in Rats
}

\author{
Fair M. Vassoler, ${ }^{1}$ Heath D. Schmidt, ${ }^{3}$ Mary E. Gerard, ${ }^{2}$ Katie R. Famous, ${ }^{1}$ Domenic A. Ciraulo, ${ }^{2}$ Conan Kornetsky, ${ }^{1,2}$ \\ Clifford M. Knapp, ${ }^{2}$ and R. Christopher Pierce ${ }^{1,2}$ \\ Departments of ${ }^{1}$ Pharmacology and ${ }^{2}$ Psychiatry, Boston University School of Medicine, Boston, Massachusetts 02118 , and ${ }^{3}$ Department of Psychiatry, Yale \\ University School of Medicine, New Haven, Connecticut 06508
}

\begin{abstract}
Increasing evidence suggests that deep brain stimulation (DBS), which is currently being used as a therapy for neurological diseases, may be effective in the treatment of psychiatric disorders as well. Here, we examined the influence of DBS of the nucleus accumbens shell on cocaine priming-induced reinstatement of drug seeking, an animal model of relapse. Rats were allowed to self-administer cocaine $(0.25$ $\mathrm{mg}$, i.v.) $2 \mathrm{~h}$ daily for $21 \mathrm{~d}$ and then cocaine-seeking behavior was extinguished by replacing cocaine with saline. During the reinstatement phase, DBS was administered bilaterally to the nucleus accumbens shell through bipolar stainless steel electrodes. Biphasic symmetrical pulses were delivered at a frequency of $160 \mathrm{~Hz}$ and a current intensity of $150 \mu \mathrm{A}$. DBS began immediately after a priming injection of cocaine $(0,5,10$, or $20 \mathrm{mg} / \mathrm{kg}$, i.p.) and continued throughout each $2 \mathrm{~h}$ reinstatement session. Results indicated that only the higher doses of cocaine (10 and $20 \mathrm{mg} / \mathrm{kg}$ ) produced robust and reliable reinstatement of cocaine seeking. DBS of the nucleus accumbens shell significantly attenuated the reinstatement of drug seeking precipitated by these higher cocaine doses. Additional experiments indicated that this DBS effect was both anatomically and reinforcer specific. Thus, DBS of the dorsal striatum had no influence on cocaine reinstatement and DBS of the accumbens shell did not affect the reinstatement of food seeking. Together, these results suggest that DBS of the nucleus accumbens shell may be a potential therapeutic option in the treatment of severe cocaine addiction.
\end{abstract}

Key words: deep brain stimulation; relapse; addiction; psychostimulant; striatum; accumbens shell

\section{Introduction}

After detoxification, the relapse rate among human cocaine addicts is discouragingly high (Carroll et al., 1994). Cravinginduced relapse of drug-taking behavior is precipitated by three major factors: a stressful life event, an environmental stimulus previously associated with drug taking, or reexposure to the drug itself (Spealman et al., 1999; Goeders, 2002; Schmidt et al., 2005; See, 2005; Epstein et al., 2006). For example, laboratory studies indicate that cocaine administration precipitates craving (i.e., the urge to use drugs) among experienced human cocaine users (Jaffe et al., 1989). Cocaine craving-induced relapse of drug taking among human addicts is modeled in rodents and monkeys by administering a noncontingent priming drug injection to animals in which cocaine self-administration behavior has been extinguished. Using this paradigm, systemic or intravenous injec-

Received Nov. 28, 2007; revised July 16, 2008; accepted July 19, 2008

This work was supported by National Institutes of Health (NIH) Grants R01 DA15214 and K02 DA18678 (R.C.P.) as well as The Gennaro Acampora Charity Trust (D.A.C.). K.R.F. was partially supported by a National Research Service Award (NRSA) from the NIH (F30 DA19304) as well as NIH Training Grant T32 GM008541-7. H.D.S. was also partially supported by an NRSA from the NIH (F31 DA16824). C.K. was partially supported by K05 DA00099 from the NIH. We thank Audrey Pierce-Bancroft for administrative assistance as well as Lisa Tozier and Steven Crosby for technical support.

Correspondence should be addressed to R. Christopher Pierce, Department of Pharmacology, L603, Boston University School of Medicine, Boston, MA 02118. E-mail: rcpierce@bu.edu.

D01:10.1523/JNEUROSCI.5277-07.2008

Copyright $\odot 2008$ Society for Neuroscience $\quad$ 0270-6474/08/288735-05\$15.00/0 tions of relatively low doses of cocaine result in robust reinstatement of cocaine-seeking behavior (Spealman et al., 1999; Shalev et al., 2002; Schmidt et al., 2005). Although considerable progress has been made in identifying the neuronal circuitry and neurochemical mechanisms underlying cocaine craving, an effective therapeutic for cocaine addiction remains elusive. Evidence obtained using the reinstatement paradigm indicates that the nucleus accumbens shell is an important locus for cocaine priming-induced reinstatement of drug-seeking behavior (Anderson et al., 2003, 2006; Bachtell et al., 2005; Schmidt et al., 2006; Schmidt and Pierce, 2006). Therefore, disruption of neuronal activity within the nucleus accumbens shell would be expected to attenuate the reinstatement of cocaine-seeking behavior precipitated by a systemic-priming injection of cocaine.

Deep brain stimulation (DBS) of thalamic, subthalamic, or pedunculopontine nuclei is effective in the treatment of Parkinson's disease (Perlmutter and Mink, 2006). Despite the risks associated with major surgery, DBS also is being tested as a therapy for psychiatric disorders and a growing literature indicates promise for this therapeutic modality (Mayberg et al., 2005). Specifically, DBS of the nucleus accumbens, including the shell subregion, has been shown to be efficacious in the treatment of refractory major depression and Tourette's syndrome as well as obsessive-compulsive and anxiety disorders (Sturm et al., 2003; Kuhn et al., 2007b; Schlaepfer et al., 2008). In addition, a case 
study indicated that DBS of the nucleus accumbens substantially reduced alcohol consumption in an alcohol-dependent patient (Kuhn et al., 2007a). It seems reasonable, therefore, to propose DBS as a potential treatment in cases of extreme (i.e., life threatening) cocaine addiction. The preclinical experiments outlined here examined the influence of DBS of the nucleus accumbens shell on cocaine priming-induced reinstatement of drug seeking.

\section{Materials and Methods}

Animals and housing. Male Sprague Dawley rats (Rattus norvegicus) weighing 250-300 g were obtained from Taconic Farms. Animals were individually housed with food and water available ad libitum. A $12 \mathrm{~h}$ light/dark cycle was used with the lights on at 7:00 A.M. All experimental procedures were performed during the light cycle.

Materials. All experiments used Med Associates instrumentation enclosed within ventilated, sound-attenuating chambers. The apparatus was equipped with response levers, stimulus lights, food pellet dispensers, and injection pumps for injecting drugs intravenously.

Surgery. Before surgery, the rats were anesthetized by intraperitoneal injections of $80 \mathrm{mg} / \mathrm{kg}$ ketamine and $12 \mathrm{mg} / \mathrm{kg}$ xylazine. An indwelling SILASTIC catheter was placed into the right jugular vein (side opposite the heart) and sutured in place. The catheter was then threaded subcutaneously over the shoulder blade and was routed to a mesh backmount platform (CamCaths) that was sutured below the skin between the shoulder blades. Catheters were flushed daily with $0.3 \mathrm{ml}$ of an antibiotic (Timentin, $0.93 \mathrm{mg} / \mathrm{ml}$ ) dissolved in heparinized saline. The catheters were sealed with plastic obturators when not in use.

After catheter implantation, the rats were mounted in a stereotaxic apparatus (Kopf Instruments), and bipolar stainless steel electrodes (Plastics One) were implanted into to the nucleus accumbens shell or dorsal striatum according to the following coordinates, relative to bregma (Paxinos and Watson, 1997): nucleus accumbens shell: $+1.0 \mathrm{~mm}$ anteroposterior $(\mathrm{A} / \mathrm{P}), \pm 3.0 \mathrm{~mm}$ mediolateral $(\mathrm{M} / \mathrm{L}),-7.3 \mathrm{~mm}$ dorsoventral (D/V); dorsal striatum: $+1.0 \mathrm{~mm} \mathrm{~A} / \mathrm{P}, \pm 4.0 \mathrm{~mm} \mathrm{M} / \mathrm{L},-5.0 \mathrm{~mm}$ $\mathrm{D} / \mathrm{V}$. The stereotaxic arms were set at $17^{\circ}$ angles for both brain regions. Electrodes were cemented in place by affixing dental acrylic to three stainless steel screws fastened to the skull.

Cocaine self-administration, extinction, and reinstatement. After a $7 \mathrm{~d}$ recovery period from surgery, the rats were placed in operant chambers and allowed to lever press for intravenous cocaine infusions $(0.25 \mathrm{mg}$ cocaine per $56 \mu \mathrm{l}$ saline per infusion over $5 \mathrm{~s}$ ). Rats initially were trained using a fixed ratio 1 (FR1) schedule of reinforcement. When the animals achieved stable responding with the FR1 schedule (i.e., $<15 \%$ variation in response rates over 3 consecutive days), they were switched to an FR5 schedule. A $20 \mathrm{~s}$ timeout period during which responses had no scheduled consequences followed each cocaine infusion. The rats were limited to a maximum of 30 cocaine infusions per daily $2 \mathrm{~h}$ self-administration session.

After $21 \mathrm{~d}$ of cocaine self-administration total, the animals underwent an extinction phase during which cocaine was replaced with saline. Daily $2 \mathrm{~h}$ extinction sessions were conducted until responding was $<15 \%$ of the response rate maintained by cocaine self-administration. After the extinction phase, priming-induced reinstatement of drug-seeking behavior was assessed via the intraperitoneal administration of $0(0.9 \%$ saline), 5, 10, or $20 \mathrm{mg} / \mathrm{kg}$ cocaine. For the reinstatement sessions the FR5 schedule was used, but satisfaction of the response requirements for each component resulted in a saline rather than a cocaine infusion. Each reinstatement session was followed by extinction sessions until responding was $<15 \%$ of the response rate maintained by cocaine selfadministration. There were typically 1 to 2 extinction days between each reinstatement session.

Using this experimental design, the rats underwent a series of extinction and reinstatement sessions that lasted $\sim 16 \mathrm{~d}$. During this period, extinction of the ability of cocaine to induce reinstatement is a concern. However, we have previously shown that reinstatement of cocaine seeking persists for at least $20 \mathrm{~d}$ after the initial extinction of cocaine selfadministration (Park et al., 2002; Anderson et al., 2003). Moreover, because the drug treatments were counterbalanced across reinstatement days, in the current experiments we were able to assess the magnitude of reinstatement across sessions. Thus, reinstatement of cocaine seeking was assessed at the beginning, middle, and end of the reinstatement phase. All subjects demonstrated stable drug seeking throughout the reinstatement phase of these experiments.

Food self-administration, extinction, and reinstatement. Rats were trained to self-administer $50 \mathrm{mg}$ Noyes sucrose pellets (Research Diets) using the same procedures described above. After 2 weeks of daily $1 \mathrm{~h}$ food-reinforced operant sessions, rats underwent an extinction phase where responding no longer resulted in food delivery. After lever pressing decreased to $15 \%$ or less of the responding maintained by contingent food reinforcement, animals began reinstatement testing. Reinstatement of food seeking was promoted by the noncontingent administration (remotely by the experimenter) of one sucrose pellet every 2 min during the first $10 \mathrm{~min}$ of the reinstatement session. Each $1 \mathrm{~h}$ reinstatement session was followed by extinction sessions (typically only one or two) until responding was again $<15 \%$ of the response rate maintained by food.

Deep brain stimulation. In most DBS experiments (both clinical and preclinical), many parameters are fixed and uniform across studies. We used continuous alternating current with biphasic symmetrical square pulses ( $60 \mu$ s pulse width, $160 \mathrm{~Hz}$ frequency), parameters that are consistent with previous work in this field (Chang et al., 2003; Mayberg et al., 2005). Stimulation intensities, in contrast, are often varied within and between studies, usually in the range of 50-200 $\mu \mathrm{A}$ (Benazzouz and Hallett, 2000; Chang et al., 2003; Mayberg et al., 2005). Immediately before the start of a reinstatement session, $70-150 \mu \mathrm{A}$ of current was delivered to the bipolar electrodes. The stimulation continued until the end of the reinstatement session.

Verification of electrode placements. After the completion of all experiments, the animals were given an overdose of pentobarbital $(100 \mathrm{mg} / \mathrm{kg})$ and perfused intracardially with $0.9 \%$ saline followed by $10 \%$ formalin. The brain was removed and coronal sections $(100 \mu \mathrm{m})$ were taken at the level of the nucleus accumbens with a Vibratome (Technical Products International). An investigator unaware of the animals' behavioral responses determined electrode placements as well as potential electrodeinduced neuronal damage. Animals with electrode placements outside of the areas of interest, or with excessive mechanical damage, were excluded from subsequent data analysis.

\section{Results}

\section{DBS of the nucleus accumbens shell attenuates cocaine} priming-induced reinstatement of drug seeking

In initial experiments, animals were administered $0,70,100$, or $150 \mu \mathrm{A}$ DBS bilaterally in the nucleus accumbens shell immediately after a priming injection of cocaine ( 0 or $10 \mathrm{mg} / \mathrm{kg}$, i.p.) during the reinstatement phase. Results indicated that only the $150 \mu \mathrm{A}$ current intensity significantly attenuated the reinstatement of cocaine seeking (data not shown). Therefore, this current intensity was used for all subsequent experiments. Notably, the behavioral hyperactivity produced by cocaine did not increase or decrease during DBS. No other abnormal behaviors of any kind were noted with cocaine plus DBS or saline pretreatment before DBS.

For the cocaine dose-response experiment summarized in Figure 1, $A$ and $B$, the number of active lever presses on the last day of cocaine self-administration was $131.46 \pm 6.35$ (mean \pm SEM). The extinction criterion was reached in $4.92 \pm 0.49$ (mean \pm SEM) d. Active lever responding on the last day of extinction was $14.46 \pm 1.03$ (mean \pm SEM).

The total active lever presses during the reinstatement phase were analyzed with a two-way ANOVA, which revealed significant main effects of cocaine dose $\left(F_{(3,77)}=18.449 ; p\right.$ $<0.0001)$ and current intensity $\left(F_{(1,77)}=11.322 ; p<0.0012\right)$ as well as a significant interaction between these factors $\left(F_{(3,77)}\right.$ $=4.996 ; p<0.0032$ ). Subsequent pairwise analyses (Fisher's LSD, $p<0.05)$ showed that the total active responses after 10 


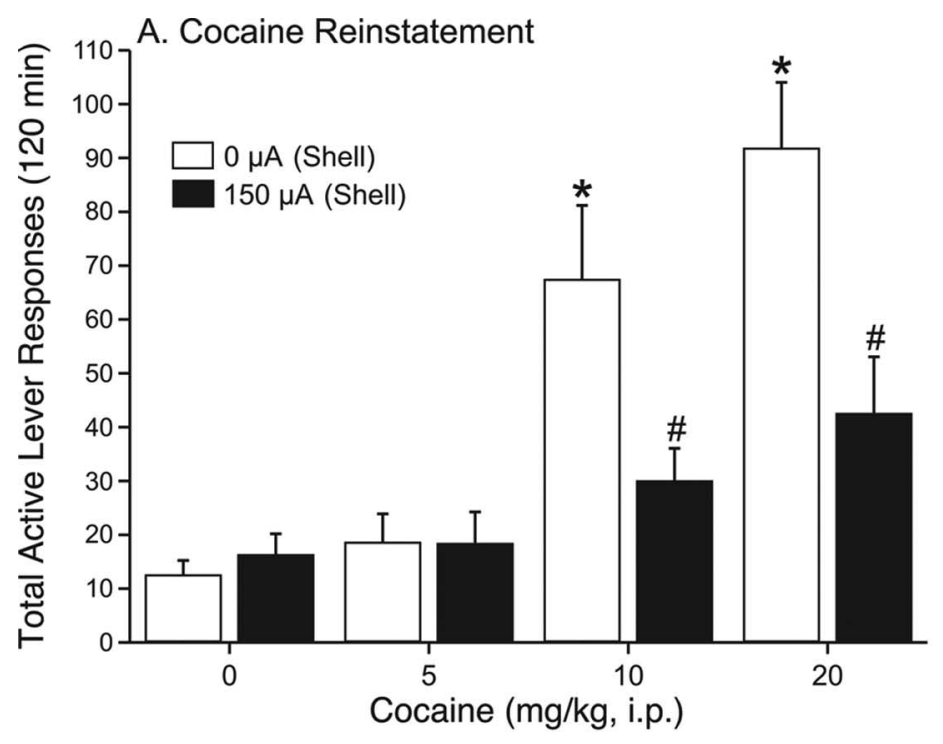

\section{Electrode Placements}
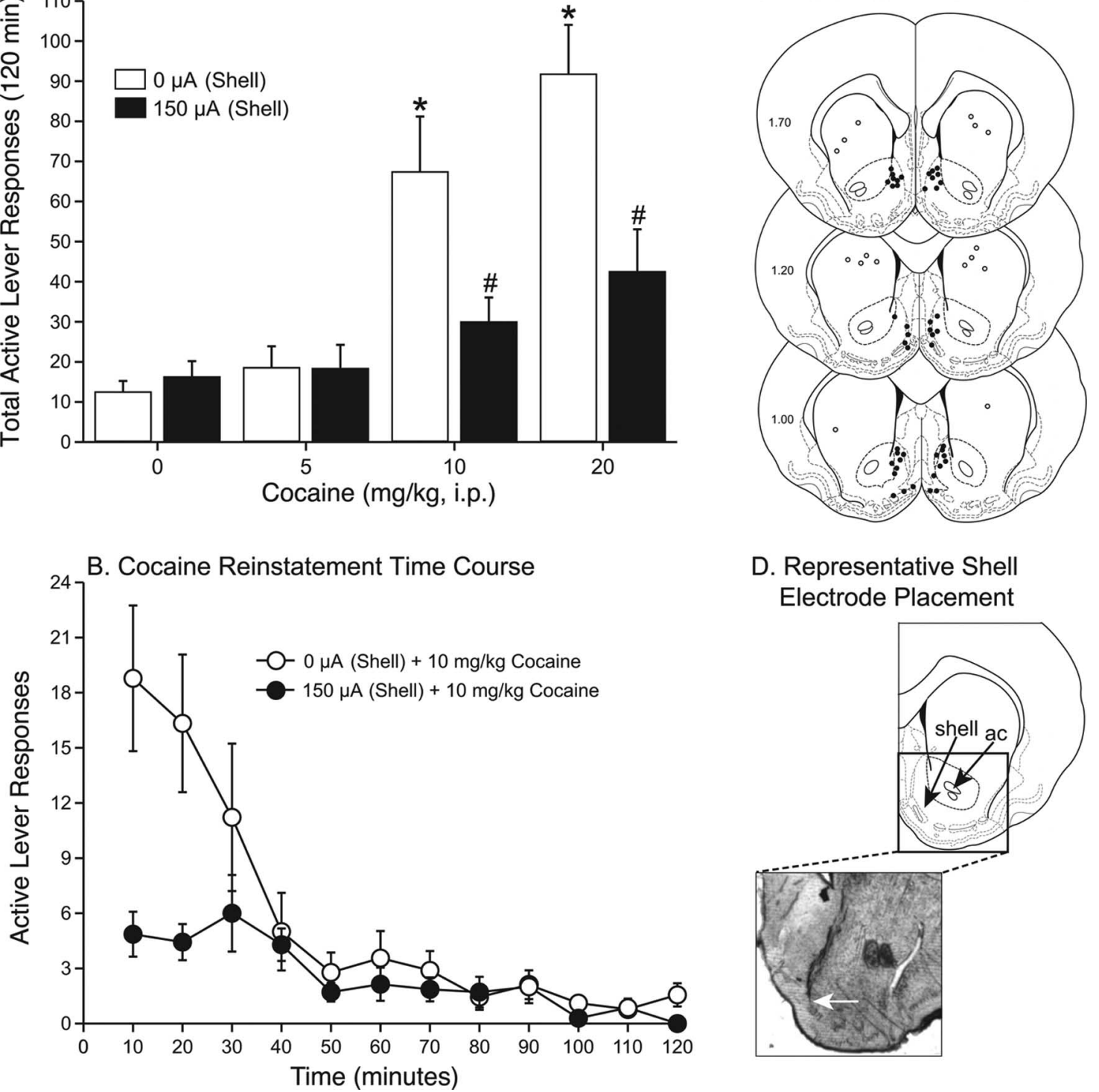

\section{Representative Shell Electrode Placement}

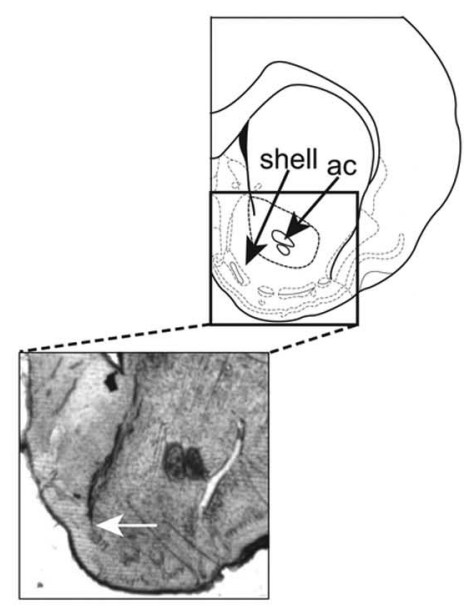

Figure 1. Deep-brain stimulation of the nucleus accumbens shell attenuated cocaine priming-induced reinstatement of drug seeking in rats. $\boldsymbol{A}$, DBS ( 0 or $150 \mu \mathrm{A}$ ) began immediately after intraperitoneal administration of $0,5,10$, or $20 \mathrm{mg} / \mathrm{kg}$ cocaine and continued throughout the $2 \mathrm{~h}$ reinstatement session $(n=7-12)$. ${ }^{*}$ Significant differences from the $0 \mu \mathrm{A} /$ saline treatment. \#Significant differences from $0 \mu \mathrm{A}$ at that cocaine dose. $\boldsymbol{B}$, The time courses of the effect of $0(n=9)$ or $150(n=7) \mu \mathrm{ADBS}$ on the reinstatement of drug seeking precipitated by $10 \mathrm{mg} / \mathrm{kg}$ cocaine from $\boldsymbol{A}$. $\boldsymbol{C}$, Electrode placements in the nucleus accumbens shell (filled circles) and dorsal striatum (open circles) for all subjects. $\boldsymbol{D}$, Representative electrode placement in the shell. The white arrow indicates the end of the electrode tract. ac, Anterior commissure.

and $20 \mathrm{mg} / \mathrm{kg}$ cocaine with no stimulation were significantly different from saline. In addition, DBS significantly attenuated the reinstatement of drug seeking precipitated by both of these higher doses of cocaine. There were 7-12 subjects per treatment. These data indicate that DBS of the nucleus accumbens shell produced a rightward (or downward) shift in the cocaine reinstatement dose-response curve (Fig. $1 A$ ). Analysis of the total inactive lever presses during the reinstatement phase (data not shown) indicated no significant main effects of cocaine dose or current intensity and no significant interaction between these factors, which suggests that neither cocaine nor DBS produced nonspecific changes in lever pressing. Figure $1 B$ depicts the time courses of the active lever responses in the 0 and $150 \mu \mathrm{A}$ plus $10 \mathrm{mg} / \mathrm{kg}$ cocaine treatments from Figure $1 A$.

\section{DBS of the dorsal striatum has no influence on the} reinstatement of cocaine seeking

In order to assess the anatomical specificity of the accumbens shell DBS effect, DBS (0 or $150 \mu \mathrm{A}$ ) was administered in the dorsal striatum during the reinstatement of drug seeking induced by an intraperitoneal-priming injection of $10 \mathrm{mg} / \mathrm{kg}$ cocaine. The data were as follows (mean active lever responses \pm SEM): $0 \mu \mathrm{A}$, $59.14 \pm 10.26 ; 150 \mu \mathrm{A}, 49.25 \pm 11.17$. These data were analyzed with a $t$ test, which revealed no significant difference between treatments $\left(t_{(14)}=0.130 ; p<0.8985\right)$. There were eight subjects per treatment.

The effect of DBS of the dorsal striatum during a reinstatement session in which a saline-priming injection was administered also was assessed. The data were as follows (mean active lever responses $\pm \mathrm{SEM}): 0 \mu \mathrm{A}, 14.63 \pm 3.35 ; 150 \mu \mathrm{A}, 12.75 \pm$ 
3.32. These data were analyzed with a paired $t$ test, which revealed no significant effect $\left(t_{(14)}=0.398 ; p<0.6969\right)$. There were eight subjects in this experiment.

\section{DBS of the nucleus accumbens shell does not affect the reinstatement of food seeking}

Several measures were used to evaluate potential nonspecific rate suppressing effects of DBS. The modular testing chambers were equipped with an inactive lever, responses on which often are used as a measure of nonspecific alterations in lever pressing during the reinstatement phase. Although DBS did not have a significant influence on responding on the inactive lever, the low number of inactive lever presses limits the utility of this measure to meaningfully assess potential rate suppressant effects. Therefore, we also assessed the effect of nucleus accumbens shell DBS $(0$ or $150 \mu \mathrm{A})$ on the reinstatement of food seeking. For this experiment, the number of active lever presses on the last day of food self-administration was $150 \pm 0$ (mean \pm SEM), the maximal number of reinforcers per session per subject. The extinction criterion was reached in $5.3 \pm 0.39$ (mean \pm SEM) $\mathrm{d}$. The data were as follows (mean active lever responses $\pm \mathrm{SEM}$ ): $0 \mu \mathrm{A}$, $48.67 \pm 10.57 ; 150 \mu \mathrm{A}, 53 \pm 9.24$. These data were analyzed with a paired $t$ test, which showed no significant treatment effect $\left(t_{(15)}\right.$ $=0.305 ; p<0.7618$ ). Four of the food reinstatement subjects had previous experience with cocaine self-administration, but this factor had no influence on food self-administration or the reinstatement of food seeking. There were eight or nine animals per treatment group.

The electrode placements in the nucleus accumbens shell and dorsal striatum for all experiments are shown in Figure 1C. A photomicrograph of a representative electrode placement in the nucleus accumbens shell is shown in Figure $1 D$. There were no instances of excessive mechanical damage induced by DBS.

\section{Discussion}

The current results indicate that (1) DBS of the nucleus accumbens shell attenuated the reinstatement of cocaine seeking; (2) DBS of the dorsal striatum had no influence on cocaine reinstatement; (3) DBS of the nucleus accumbens shell did not affect the reinstatement of food seeking; and (4) DBS of the accumbens shell in the absence of a cocaine-priming injection did not promote the reinstatement of cocaine seeking. Collectively, these results demonstrate that DBS of the nucleus accumbens shell attenuates the reinstatement of cocaine seeking in an anatomically and reinforcer-specific manner.

In studies of parkinsonism, depression, and anxiety disorders, clinical measurements are made during DBS and compared with measurements when the stimulation is off. The stimulation is constant and the effects are completely reversed when the stimulation is turned off. For example, the antidepressant effect of continuous DBS was immediate, bidirectional, and reversible (Schlaepfer et al., 2008). That is, when the stimulator was turned on, depression ratings immediately improved, and when it was turned off, depression ratings worsened (Schlaepfer et al., 2008). Similar to clinical studies, DBS was administered continuously during the reinstatement session in the current experiments.

The clinical effect of DBS at high frequencies is due at least in part to the suppression of neuronal activity via the activation of inhibitory interneurons and/or depolarization inactivation (Benabid et al., 1991; Blond et al., 1992). Consistent with the view that DBS produces its effects by reversible neuronal inactivation, intra-accumbal administration of an AMPA receptor antagonist, which blocks excitatory neurotransmission, attenuates cocaine priming-induced reinstatement of cocaine seeking (Cornish et al., 1999; Cornish and Kalivas, 2000; Park et al., 2002). In contrast, activation of the nucleus accumbens with an AMPA microinjection promotes the reinstatement of cocaine seeking (Cornish et al., 1999; Cornish and Kalivas, 2000). However, there also is evidence that DBS inactivates cell bodies but activates axons in the stimulated area (Vitek, 2002; McIntyre et al., 2004). Consistent with this notion, DBS of the nucleus accumbens core suppressed neuronal activity in the orbitofrontal cortex apparently via antidromic stimulation of cortico-accumbal afferents and the subsequent activation of inhibitory cortical interneurons (McCracken and Grace, 2007). Potential DBS-induced inactivation of accumbal afferents is particularly significant given mounting evidence that activation of excitatory medial prefrontal cortical and orbitofrontal cortical afferents to the nucleus accumbens promotes the reinstatement of cocaine seeking (Park et al., 2002; McFarland et al., 2003; Fuchs et al., 2004). Together, these results suggest that DBS of the nucleus accumbens shell attenuates cocaine seeking by inhibiting neuronal activity in accumbal output neurons and/or inactivation of accumbal afferents.

It is well known that animals will self-stimulate various brain areas, including the nucleus accumbens (Mogenson et al., 1979; West and Wise, 1988). The electrical impulses that rats learn to self stimulate are brief (usually lasting less than $1 \mathrm{~s}$ ) and stimulate neuronal activity (Wise et al., 1992). Previous evidence indicates that only the initial onset of brain stimulation is reinforcing (Pollock and Kornetsky, 1990). In contrast, in the present experiments, high frequency DBS was administered continuously throughout the reinstatement session to suppress neuronal activity. It has been shown that noncontingent stimulation can be aversive, even when the stimulation is identical to the selfadministered pattern (Steiner et al., 1969). Importantly, clinical studies report that prolonged and continuous DBS of the nucleus accumbens is neither reinforcing nor aversive (Sturm et al., 2003; Kuhn et al., 2007a; Okun et al., 2007; Schlaepfer et al., 2008). The present results support this clinical observation. DBS of the nucleus accumbens shell in the absence of a cocaine-priming injection failed to promote drug seeking, which suggests that DBS is unlikely to promote drug craving. It is also notable that DBS of the nucleus accumbens shell did not attenuate food-seeking behavior in rats, which indicates that DBS does not produce a generalized disruption of normal behavior. Although it is unclear exactly why DBS of the nucleus accumbens shell produced reinforcer specific effects in the current study, it is likely because the neuronal circuits subserving cocaine and food-seeking behaviors are at least partially segregated (Carelli et al., 2000; Horvath and Diano, 2004).

In conclusion, the present results indicated that DBS of the nucleus accumbens shell blunts the reinstatement of drug seeking produced by reexposure to cocaine. This effect was anatomically specific in that DBS of the dorsal striatum did not influence cocaine reinstatement. In addition, DBS of the accumbens shell failed to influence the reinstatement of food seeking, which indicates that the DBS effect was selective to cocaine and not attributable to a generalized disruption in motivated behavior. Together, these results indicate that DBS of the nucleus accumbens shell may represent a novel therapeutic modality for the treatment of severe cocaine addiction.

\section{References}

Anderson SM, Bari AA, Pierce RC (2003) Administration of the D1-like dopamine receptor antagonist SCH-23390 into the medial nucleus accumbens shell attenuates cocaine priming-induced reinstatement of drug-seeking behavior in rats. Psychopharmacology (Berl) 168:132-138. 
Anderson SM, Schmidt HD, Pierce RC (2006) Administration of the D2 dopamine receptor antagonist sulpiride into the shell, but not the core, of the nucleus accumbens attenuates cocaine priming-induced reinstatement of drug seeking. Neuropsychopharmacology 31:1452-1461.

Bachtell RK, Whisler K, Karanian D, Self DW (2005) Effects of intranucleus accumbens shell administration of dopamine agonists and antagonists on cocaine-taking and cocaine-seeking behaviors in the rat. Psychopharmacology (Berl) 183:41-53.

Benabid AL, Pollak P, Gervason C, Hoffmann D, Gao DM, Hommel M, Perret JE, de Rougemont J (1991) Long-term suppression of tremor by chronic stimulation of the ventral intermediate thalamic nucleus. Lancet 337:403-406.

Benazzouz A, Hallett M (2000) Mechanism of action of deep brain stimulation. Neurology 55:S13-S16.

Blond S, Caparros-Lefebvre D, Parker F, Assaker R, Petit H, Guieu JD, Christiaens JL (1992) Control of tremor and involuntary movement disorders by chronic stereotactic stimulation of the ventral intermediate thalamic nucleus. J Neurosurg 77:62-68.

Carelli RM, Ijames SG, Crumling AJ (2000) Evidence that separate neural circuits in the nucleus accumbens encode cocaine versus "natural" (water and food) reward. J Neurosci 20:4255-4266.

Carroll KM, Rounsaville BJ, Nich C, Gordon LT, Wirtz PW, Gawin F (1994) One-year follow-up of psychotherapy and pharmacotherapy for cocaine dependence. Delayed emergence of psychotherapy effects. Arch Gen Psychiatry 51:989-997.

Chang JY, Shi LH, Luo F, Woodward DJ (2003) High frequency stimulation of the subthalamic nucleus improves treadmill locomotion in unilateral 6-hydroxydopamine lesioned rats. Brain Res 983:174-184.

Cornish JL, Kalivas PW (2000) Glutamate transmission in the nucleus accumbens mediates relapse in cocaine addiction. J Neurosci 20:RC89.

Cornish JL, Duffy P, Kalivas PW (1999) A role for nucleus accumbens glutamate transmission in the relapse to cocaine-seeking behavior. Neuroscience 93:1359-1367.

Epstein DH, Preston KL, Stewart J, Shaham Y (2006) Toward a model of drug relapse: an assessment of the validity of the reinstatement procedure. Psychopharmacology (Berl) 189:1-16.

Fuchs RA, Evans KA, Parker MP, See RE (2004) Differential involvement of orbitofrontal cortex subregions in conditioned cue-induced and cocaineprimed reinstatement of cocaine seeking in rats. J Neurosci 24:6600-6610

Goeders NE (2002) Stress and cocaine addiction. J Pharmacol Exp Ther 301:785-789.

Horvath TL, Diano S (2004) The floating blueprint of hypothalamic feeding circuits. Nat Rev Neurosci 5:662-667.

Jaffe JH, Cascella NG, Kumor KM, Sherer MA (1989) Cocaine-induced cocaine craving. Psychopharmacology (Berl) 97:59-64.

Kuhn J, Lenartz D, Huff W, Lee S, Koulousakis A, Klosterkoetter J, Sturm V (2007a) Remission of alcohol dependency following deep brain stimulation of the nucleus accumbens: valuable therapeutic implications? J Neurol Neurosurg Psychiatry 78:1152-1153.

Kuhn J, Lenartz D, Mai JK, Huff W, Lee SH, Koulousakis A, Klosterkoetter J, Sturm V (2007b) Deep brain stimulation of the nucleus accumbens and the internal capsule in therapeutically refractory Tourette-syndrome. J Neurol 254:963-965.

Levy D, Shabat-Simon M, Shalev U, Barnea-Ygael N, Cooper A, Zangen A (2007) Repeated electrical stimulation of reward-related brain regions affects cocaine but not "natural" reinforcement. J Neurosci 27:14179-14189.

Mayberg HS, Lozano AM, Voon V, McNeely HE, Seminowicz D, Hamani C, Schwalb JM, Kennedy SH (2005) Deep brain stimulation for treatmentresistant depression. Neuron 45:651-660.

McCracken CB, Grace AA (2007) High-frequency deep brain stimulation of the nucleus accumbens region suppresses neuronal activity and selectively modulates afferent drive in rat orbitofrontal cortex in vivo. J Neurosci 27:12601-12610.

McFarland K, Lapish CC, Kalivas PW (2003) Prefrontal glutamate release into the core of the nucleus accumbens mediates cocaine-induced reinstatement of drug-seeking behavior. J Neurosci 23:3531-3537.

McIntyre CC, Savasta M, Walter BL, Vitek JL (2004) How does deep brain stimulation work? Present understanding and future questions. J Clin Neurophysiol 21:40-50.

Mogenson GJ, Takigawa M, Robertson A, Wu M (1979) Self-stimulation of the nucleus accumbens and ventral tegmental area of Tsai attenuated by microinjections of spiroperidol into the nucleus accumbens. Brain Res 171:247-259.

Okun MS, Mann G, Foote KD, Shapira NA, Bowers D, Springer U, Knight W, Martin P, Goodman WK (2007) Deep brain stimulation in the internal capsule and nucleus accumbens region: responses observed during active and sham programming. J Neurol Neurosurg Psychiatry 78:310-314.

Park WK, Bari AA, Jey AR, Anderson SM, Spealman RD, Rowlett JK, Pierce RC (2002) Cocaine administered into the medial prefrontal cortex reinstates cocaine-seeking behavior by increasing AMPA receptor-mediated glutamate transmission in the nucleus accumbens. J Neurosci 22:2916-2925.

Paxinos G, Watson C (1997) The rat brain in stereotaxic coordinates. New York: Academic.

Perlmutter JS, MinkJW (2006) Deep brain stimulation. Annu Rev Neurosci 29:229-257.

Pollock J, Kornetsky C (1990) Pharmacologic evidence for nociception resulting from noncontingent "rewarding" brain stimulation. Physiol Behav 47:761-765.

Schlaepfer TE, Cohen MX, Frick C, Kosel M, Brodesser D, Axmacher N, Joe AY, Kreft M, Lenartz D, Sturm V (2008) Deep brain stimulation to reward circuitry alleviates anhedonia in refractory major depression. Neuropsychopharmacology 33:368-377.

Schmidt HD, Pierce RC (2006) Systemic administration of a dopamine, but not a serotonin or norepinephrine, transporter inhibitor reinstates cocaine seeking in the rat. Behav Brain Res 175:189-194.

Schmidt HD, Anderson SM, Pierce RC (2006) Stimulation of D1-like or D2 dopamine receptors in the shell, but not the core, of the nucleus accumbens reinstates cocaine-seeking behavior in the rat. Eur J Neurosci 23:219-228.

Schmidt HD, Anderson SM, Famous KR, Kumaresan V, Pierce RC (2005) Anatomy and pharmacology of cocaine priming-induced reinstatement of drug seeking. Eur J Pharmacol 526:65-76.

See RE (2005) Neural substrates of cocaine-cue associations that trigger relapse. Eur J Pharmacol 526:140-146.

Shalev U, Grimm JW, Shaham Y (2002) Neurobiology of relapse to heroin and cocaine seeking: a review. Pharmacol Rev 54:1-42.

Spealman RD, Barrett-Larimore RL, Rowlett JK, Platt DM, Khroyan TV (1999) Pharmacological and environmental determinants of relapse to cocaine-seeking behavior. Pharmacol Biochem Behav 64:327-336.

Steiner SS, Beer B, Shaffer MM (1969) Escape from self-produced rates of brain stimulation. Science 163:90-91.

Sturm V, Lenartz D, Koulousakis A, Treuer H, Herholz K, Klein JC, Klosterkötter J (2003) The nucleus accumbens: a target for deep brain stimulation in obsessive-compulsive- and anxiety-disorders. J Chem Neuroanat 26:293-299.

Vitek JL (2002) Mechanisms of deep brain stimulation: excitation or inhibition. Mov Disord 17 [Suppl 3]:S69-S72.

West TE, Wise RA (1988) Effects of naltrexone on nucleus accumbens, lateral hypothalamic and ventral tegmental self-stimulation rate-frequency functions. Brain Res 462:126-133.

Wise RA, Bauco P, Carlezon WA Jr, Trojniar W (1992) Self-stimulation and drug reward mechanisms. Ann N Y Acad Sci 654:192-198. 